\title{
TESTE "IN VITRO" DE EFICÁCIA DO CINAMOMO (MELIA AZEDARCH, L.) SOBRE FÊMEAS INGURGITADAS DO BOOPHILUS MICROPLUS, CAN. (ACARI:IXODIDAE)
}

\author{
Ligia Miranda Ferreira Borges "* Andréa Caetano Da Silva "* \\ Belmiro Pereira Das Neves
}

\section{RESUMO}

" A eficácia do extrato oleoso do fruto do cinamomo (Melia azedarach,L.) foi avaliada em fêmeas ingurgitadas do Boophilus microplus colhidas em cinco propriedades rurais da Microrregião de Goiânia, Go. A inibição da postura variou de $65,7 \%$ a $99,8 \%$, enquanto que a inibição da eclodibilidade variou de $84,2 \%$ a $100,0 \%$. As médias das eficácias foram de $99,1 \%, 99,2 \%$ e $100,0 \%$ para as diluições de $0,25 \%$, $0,50 \%$ e $1,00 \%$, respectivamente.

UNITERMOS: Melia azedarach, Boophilus microplus, bovinos

\section{INTRODUÇÃO}

O Boophilus microplus é espécie de carrapato de maior distribuição geográfica e importância econômica para os principais países produtores de bovinos situados entre os paralelos $30^{\circ}$ norte e sul.

O controle deste carrapato por meios químicos é o método mais empregado durante a sua vida parasitária. No entanto, começa a tornar-se cada vez mais difícil

-. Trabalho parcialmente financiado pela FUNAPE/PRPPG - UFG

Profa. do Depto. de Parasitologia . IPTSP/UFG. Caixa Postal 131, CEP.74001-970. Goiânia - Go.

Pesquisador da EMBRAPA/CNPAF - Rod.Gyn 12 Km10, Caixa Postal 179, CEP.74.001-970. Goiânia_GO.

Recebido para publicação em 13/07/94 
BORGES,L.M.F,;SILVA,A.C.da.; \& NEVES,B.P.das. Teste "In Vitro" de Eficácia do Cinamomo
(Melia azedarch,L) (Melia azedarch,L.) sobre Fêmeas Ingurgitadas do Boophilus microplus, Can.(Acari:Ixodidae). Rev.Pat.Trop., 23 ( 2):175-179, jul./dez.1994

devido à sua capacidade de desenvolver resistência à maioria dos acaricidas de uso corrente. Neste sentido, a descoberta de novos carrapaticidas torna-se fundamental.

SHUMUTTERER (1990) relatou que existem mauitas plantas com propriedades inseticidas por repelir, impedir a alimentação ou alterar a fisiologia de espécimens.

O cinamomo (Melia azedarach L.) é planta largamente cultivada com fins ornamentais, pertencente à família Meliaceae e originária do continente asiático (Índia,Pércia e China). Segundo Ruiz-Teran (1972) citado por SCHINEIDER et al. (1987) é conhecida pelos nomes de "Paraíso " na Argentina, "China-berry" ou " Persian Lilac" nos USA, "Lilaia" em Porto Rico e "Cinamomo Gigante" no Brasil. Esta planta contém inúmeros terpenóides com ação tóxica (LAVIE \& JAIN, 1967) e seus efeitos têm sido avaliados, em testes laboratoriais, sobre o Panstrongylus megistus (Hemiptera: Reduviidae) (SCHETZ et al., 1992); Epilachna varivestis (Coleoptera: Coccinelidae) (ZHU \& ERMEL, 1991), dentre outros.

Contudo, seu efeito como carrapaticida ainda não foi avaliado. Neste sentido delineou-se este experimento visando avaliar a eficácia do extrato do fruto do cinamomo sobre fêmeas ingurgitadas do B.microplus.

\section{MATERIAIS E MÉTODOS}

Fêmeas ingurgitadas de B.microplus foram colhidas em 5 propriedades rurais pertencentes à Microrregião de Goiânia, Go.

Após contagem e seleção dos melhores espécimens, o total selecionado foi pesado em balança analítica com precisão de $0,0001 \mathrm{~g}$. Foram formados três a quatro grupos, conforme a quantidade de espécimens, com pesos equivalentes, contendo, cada um, 10 fêmeas ingurgitadas.

O cinamomo foi utilizado sob a forma de extrato oleoso obtido através da trituração dos frutos tendo como extrator o clorofórmio. Foram feitas três diluiçães $(0,25 \%,(1,50 \%$ e $1,00 \%)$ do extrato em água. O grupo controle foi banhado em água.

Foi utilizado o teste "in vitro" por imersão de fêmeas ingurgitadas preconizado por DRUMMOND et al. (1973).

Após a imersão, as fêmeas foram secas com papel, armazenadas em placas de Petri previamente identificadas com a origem, data, diluição e peso do lote e mentidas em estufapara BOD à temperatura de $27+/-1^{\circ} \mathrm{C}$ e umidade relativa superior a $80 \%$.

Após 20 dias do início dos testes, as posturas de cada lote foram pesadas e acondicionadas em seringas plásticas, descartáveis, de $10 \mathrm{ml}$, adaptadas para esta finalidadee mantidas nas mesmas condições mencionadas anteriormente.
BORGES,L.M.F.;SILVA,A.C.da.; \& NEVES,B.P.das. Teste "In Vitro" de Eficácia do Cinamome (Melia azedarch,L.) sobre Fêmeas Ingurgitadas do Boophilus microplus, Can.(Acari:Ixodidae) Rev.Pat.Trop., 23 ( 2 ):175-179, jul./dez.1994 eclosão.

No 45o. dia após o início dos testes foi feita a leitura visual do percentual de fórmulas:

$E R=$ peso dos ovos $(\mathrm{g}) \times \%$ de eclosão $\times 20.000$

peso do lote $(\mathrm{g})$

$\mathrm{ER}=$ eficiência reprodutiva

$\mathrm{EC}=\underline{\mathrm{ER}(\text { lote controle })-\mathrm{ER} \text { (lote tratado) } \times 100}$

ER (lote controle)

$\mathrm{EC}=$ eficiência carrapaticida

Os percentuais de inibição de postura e de eclodibilidade foram calculados em relação aos lotes controle considerando a conversão em ovos e eclodibilidade destes lotes como $100 \%$.

\section{RESULTADOS E DISCUSSÃO}

Os resultados (TABELA 1) evidenciaram que o extrato possui atividade ovariostática, com inibição da postura variando de $65,7 \%$ a $99,8 \%$; e ação antiembriogênica, com inibição da eclodibilidade variando de $84,2 \%$ a $100 \%$. Estes efeitos se devem, possivelmente, à presença da azadirachtin como um dos ingredientes da Melia azedarach. Sendo este, responsável, através de alteraçóes no equilíbrio hormonal, pela redução da fecundidade de fêmeas e esterilidade parcial ou total dos ovos de espécies de diversas ordens de insetos (SCHUMUTTERER, 1988).

$\mathrm{O}$ extrato do cinamomo ainda se encontra em fase de desenvolvimento e foi utilizado na forma oleosa. O óleo por não diluir bem em água, pode ter dificultado o contato das fêmeas ingurgitadas com o princípio ativo. Ainda assim, as médias das eficácias foram de $99,1 \%, 99,2 \%$ e $99,3 \%$, respectivamente nas diluições de $0,25 \%$, $0,50 \%$ e $1,00 \%$. Vale salientar que mesmo na propriedade em que a eficácia foi mais baixa (P3) os índices obtidos foram mais altos do que aqueles recomendados pelo 
BORGES,L.M.F.;SILVA,A.C.da.; \& NEVES,B.P.das. Teste "In Vitro" de Eficácia do Cinamomo (Mella azedarch,L.) sobre Fêmeas Ingurgitadas do Boophilus microplus, Can.(Acari:Ixodidae). Rev.Pat.Trop., 23 ( 2 ):175-179, jul./dez.1994

Ministério da Agricultura, para teste "in vitro" com produtos carrapaticidas (MINISTÉRIO DA AGRICULTURA, 1990).

Outros estudos já estão sendo realizados acerca desta planta procurando viabilizar sua utilização no controle deste ectoparasito.

TABELA 1. Atividade carrapaticida de três diluiçð̃es do extrato do fruto do cinamomo sobre fêmeas ingurgitadas do B.microplus provenientes de cinco propriedades (P) da Microrregiåo de Goiânia-Go, 1993

\begin{tabular}{|c|c|c|c|c|c|c|c|}
\hline & $\begin{array}{l}\text { DIL } \\
(\%)\end{array}$ & $\begin{array}{c}\text { PESO } \\
\text { LOTE (g) }\end{array}$ & $\begin{array}{c}\text { PELO } \\
\text { POST (\%) } \\
\end{array}$ & $\begin{array}{l}\text { INIB } \\
\text { POST }\end{array}$ & ECLOD & $\begin{array}{c}\text { INIB } \\
\text { ECLOD }\end{array}$ & $\begin{array}{c}\text { EFIC } \\
(\%)\end{array}$ \\
\hline \multirow[t]{4}{*}{1} & 0,25 & 2,0017 & 0,0642 & 92,6 & 0 & 100,0 & 100,0 \\
\hline & 0,50 & 1,7363 & 0,1125 & 84,9 & 10 & 88,2 & 98,2 \\
\hline & 1,00 & 1,7853 & 0,1080 & 86,1 & 0 & 100,0 & 100,0 \\
\hline & Controle & 2,0473 & 0,885 & - & 85 & - & - \\
\hline \multirow[t]{3}{*}{2} & 0,50 & 1,6728 & 0,1807 & 78,2 & 5 & 94,4 & 98,8 \\
\hline & 1,00 & 1,6443 & 0,2069 & 74,6 & 0 & 100,0 & 100,0 \\
\hline & Controle & 1,6720 & 0,8295 & - & 90 & - & - \\
\hline \multirow[t]{3}{*}{3} & 0,25 & 1,5890 & 0,3284 & 65,7 & 10 & 89,5 & 96,4 \\
\hline & 1,00 & 1,9541 & 0,2266 & 76,3 & 15 & 84,2 & 96,3 \\
\hline & & 1,9403 & 0,9500 & - & 95 & - & - \\
\hline \multirow[t]{4}{*}{4} & 0,25 & 1,9561 & 0,0378 & 96,6 & 0 & 100,0 & 100,0 \\
\hline & 0,50 & 1,9549 & 0,0391 & 96,4 & 0 & 100,0 & 100,0 \\
\hline & 1,00 & 1,9501 & 0,0017 & 99,8 & 0 & 100,0 & 100,0 \\
\hline & Controle & 1,9747 & 0,0017 & - & 95 & - & - \\
\hline \multirow[t]{4}{*}{5} & 0,25 & 2,0632 & 0,1275 & 96,6 & 0 & 100,0 & 100,0 \\
\hline & 0,50 & 2,1015 & 0,2390 & 96,4 & 0 & 100,0 & 100,0 \\
\hline & 1,00 & 1,9501 & 0,0017 & 99,8 & 0 & 100,0 & 100,0 \\
\hline & Controle & 1,9747 & 1,0968 & - & 95 & - & - \\
\hline
\end{tabular}

\section{SUMMARY}

"In Vitro" Efficacy of Melia azedarach,L. Oily Extract Against Boophilus microplus, can Engorged Females.

The efficacy of Melia azedarach oily extract Boophilus microplus engorged females from properties of Microarea of Goiânia, Go was evaluated. The laying
BORGES,L.M.F.;SILVA,A.C.da.; \& NEVES,B.P.das. Teste "In Vitro" de Eficácia do Cinamomo (Melia azedarch,L.) sobre Fêmeas Ingurgitadas do Boophilus microplus, Can.(Acari:Ixodidae). Rev.Pat.Trop., 23 ( 2):175-179, jul./dez.1994

inhibition varied from $65,7 \%$ to $99,8 \%$ and the eclodibility varied from $84,2 \%$ to $100,0 \%$. the means of efficacies were $99,1 \%, 99,2 \%$ and $99,3 \%$ for the $0,25 \%, 0,50 \%$ and $1,00 \%$ dilutions, respectivelly.

KEYWORDS: Melia azedarch, Boophilus microplus, bovines

\section{REFERÊNCIAS BIBLIOGRÁFICAS}

01. DRUMOND, R .O.; ERNEST, S.E.; TREVINO,J.L; GLADNEY,W.J \& GRAHAM,O.H. Boophilus annulatus and B.microplus. Laboratory tests of insecticides. J.Econ.Entomol., 66 (1): 130-3, 1973.

02. LAVIE,D. \& JAIN,M.K. Tetranortriterpenoide from Melia azedarach L. Chem.Communs, p.278-80, 1967,

03. MINISTÉRIO DA AGRICULTURA. Portaria No.90: normas para produção, controle e utilização de produtos antiparasitários. Diário Oficial, seção I, p 1506-10, 22/jan./90.

04. SCHETZ,M.J.C; HADJ-IDRIS, A.E.Q; BRASILEIRO,V.L.F \& CHIAPPETA, A.A. Efeitos de extratos "in natura" de Melia azedarach Meliaceae) sobre Panstrongylus megistus (Hemiptera: Reduviidae). Mem.Inst.Oswaldo Cruz, 87 (supl.2):221, 1992.

05. SCHNEIDER,P.R.;LONGHI,S.J. \& FINGER,C.A.G. Cultura do cinamomo. Santa Maria: CEPEF/FATEC, 1987, 23P.

06. SHUMUTTERER,H. Potential of azadirachtin-containing pesticides for integrated pest control in developing and industialized contries. J. Insect Physiol.,34 (7): 713-9, 1988.

07. SHUMUTTERER,H. Properties and potential of natural pesticides from the tree, Azadirachta indica. An.Rev.of Entomol., 35:271-98, 1990.

08. ZHU, J. \& ERMEL,K. isolation of substance with growth-disturbingm properties on the Mexican bean beetle Epilachna varivestis Muls.,from the leaves of Melia azedarach L. Pflanzenkr flanzenscultz, 98 (4): 422-7,1991. 